\title{
Востоковедное знание в системе гуманитарного образования в России: размышления преподавателя вуза
}

\begin{abstract}
Аннотахия: в статье представлены размышления преподавателя вуза о проблемах интеграции достижений востоковедения в современную систему гуманитарного образования в России. Одну из проблем преподавания специальных гуманитарных дисииплин автор статьи видит в отставании содержания курсов от новейших наработок отечественного востоковедения, которые остаются достоянием учёных-востоковедов. Автор приводит примеры из собственной педагогический практики преподавания сочиологчческих дисчиплин и показывает необходимость интеграиии востоковедной проблематики в гуманитарные курсы как общего, так и специального иикла. Помимо углубления знаний о сочиокуль турной реальности и понимания собственной странъ, востоковедное знание способствует достижению общепросветительских целей - преодолению негативньх стереотипов в отношении других народов, стран и култпур, расширению горизонтов мышления, привитию навыков понима ния Другого, а также пониманию универсального и особенного в развитии России.
\end{abstract}

Ключевые слова: история, востоковедение, сочиология, наука, образование, Россия, Восток, традииия, модернизачия, просвещение.

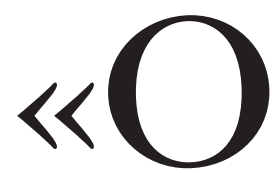

бъективный исторический ана -

лиз выявляет ...превосходство За

пада в воздействии на формирование мира, однако вместе

с тем показывает его незавершённость и недостаточность, в силу которых вопросы, обращённые к Востоку, всегда остаются современными и плодотворными, - писал в 1948 году К. Ясперс в книге “Истоки истории и её цель”. - Они г ласят: что можно там найти, чтобы дополнить это недостающее нам? Что стало там действительным, что истиной, упрощённой нами? Какова цена нашего

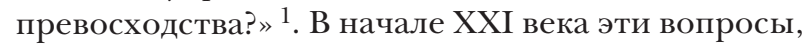
равно как и тема взаимной потребности Запада и Востока друг в друге в контексте универсальной человеческой истории, их взаимной незавершённости, взаимонедостаточности нисколько не утратили своей актуальности; более того, она только возрастает как в социально-онтологическом, так и в научно-эпистемологическом плане, в том числе - в аспекте трансляции современного социогуманитарного знания в систему образования, особенно высшего.

\footnotetext{
1 Ясперс К. Смысл и назначение истории. Пер. с нем. 2-е изд. М.: Республика, 1994. С. 90.
}

По моему глубокому убеждению, современное высшее образование призвано всеми средствами способствовать развитию свободного и самостоятельного мышления молодого человека; тем более это справедливо для современного гуманитарного образования, дисциплин гуманитарного цикла, которые изучают все без исключения студенты вузов в той или иной мере - независимо от получаемой профессии и специализации. Но самостоятельное и свободное мышление развивается только тог да, когда человек, с одной стороны, не воспринимает догматически, как истину с последней инстанции всё, что написано в учебниках или сказано преподавателем, с другой же стороны - не просто мыслит, основываясь на «встроенных» в его сознании в ходе социализации и образования моделях мышления, но и осознаёт , каким образом он осваивает и добывает знание. Иными словами, ког да он умеет осознанно пользоваться разного рода методологическими инструментами - теориями, подходами, методами и категориями, чётко понимая, что каждая теория - одна из многих возможных и равноправных «систем символического описания» (П. А. Флоренский) реальности (но не сама эта реальность!). В этом смысле полезно вспомнить размышления аргентинского писателя Эрнесто Саба- 
то: «...Для человека учиться должно означать принимать участие, открывать и изобретать. Чтобы двигаться вперёд, нужно иметь собственное мнение, даже если иной раз оно ошибочно, и нужно вновь возвращаться к самому началу . Люди должны искать новые пути, испытывать новые методы. Иначе мы в лучшем случае превратимся в книжных червей, а в ху дшем - в попугаев, твердящих готовые фразы из книг. <..> Ученик должен научиться задавать вопросы самому себе, должен быть убеждён в своём и нашем общем невежестве, и поэтому не только спрашивать, но и искать ответы, самостоятельно мыслить, даже если его взг ляды расходятся с нашими» ${ }^{2}$.

В самом общем смысле гуманитарное образование, как и отдельные гуманитарные дисциплины, так или иначе снабжают человека различными теоретическими инструментами, позволяя ему - при желании и необходимости - анализировать человеческую и социальную реальность и делать о ней выводы. Неслучайно в программах этих дисциплин одними из первых оказываются темы, посвящённые специальным теориям, подходам и методологии исследований. В большинстве своём эти теории продукт динамичного развития науки Запада - Европы и Америки, однако создавались они с целью предложить варианты анализа и интерпретации человеческой и социальной реальности как на Западе, так и на Востоке и - шире - во всех странах незападного ареала. В этом стремлении к универсальности интерпретации была заложена и востребованность этих теорий в востоковедении, и впечатляющие результаты их применения и - не менее - их критики и пересмотра - в ходе анализа восточных социокультурных систем и ментальности.

Много лет занимаясь исследованием индийской философии и культуры Нового времени и параллельно читая ряд социологических дисциплин в университете, я пришла к неутешительному выводу: вузовское гуманитарное образование в России ориентировано на освоение знания о западной и российской культуре, истории, науке, социальной реальности, а знание о Востоке - странах, народах, истории и куль туре, специфике обществ традиционных и модернизирующихся - остаётся невостребованным, исключая лишь специализированные факультеты вузов, предлагающих филологическое, философское или историческое образование соответствующих специальностей. И это в России, для познания и понимания которой знания только о Западе абсолютно недостаточно, и требуется

\footnotetext{
${ }^{2}$ Сабато Эрнесто. Умение удивляться // Курьер ЮНЕСКО.
} 1990. Октябрь. С. 7. хорошее углублённое знание специфики Востока, специфики развития его разных социокуль турных ареалов - Ближнего и Среднего Востока, Юго-Восточной Азии, Дальнего Востока... Это отсутствие востребованности востоковедного знания проявляется, во-первых, в общем невнимании к востоковедной проблематике при написании учебников и учебных пособий (максимум она присутствует как иллюстративный материал, далеко не всег да корректный). Во-вторых, это очевидно в существовании востоковедения и образования словно в двух параллельных измерениях: новейшие дискуссии теоретико-методологического плана и новейшие востоковедные исследования остаются достоянием учёных-востоковедов и практически не транслируются в содержание программ гуманитарных дисциплин, преподаваемых в вузах.

Приведу несколько примеров из собственной педагогической практики, чтобы показать, с одной стороны, насущную необходимость обогащения курсов востоковедным материалом как теоретического, так и практического характера, а с другой важность универсального видения процессов, происходящих в обществах Востока и Запада.

В курсе «Методология социального познания», рассматривая общие принципы, применяемые с познании социальных процессов, я считаю необходимым говорить о типах историзма при освещении принципа историзма. Линейный векторный историзм - интегральная часть характерной для западной науки модели мышления об обществе, и она практически со школьных лет встроена в представления сту дентов и существует в них автоматически. Между тем историзм, по определению томского историка-востоковеда О. В. Хазанова - это «представления людей о процессах, происходящих во времени, в которых так или иначе принимает участие сам человек - на личном уровне или в составе какой-либо социальной группы» ${ }^{3}$, и эти представления не всег да линейны. В связи с этим возникает вопрос о пространственных моделях исторического времени, которые - все без исключения - сформировались на Древнем Востоке. Это циклическая модель, появляющаяся уже в мифологическом мышлении и затем трансформирующаяся в философские представления, линейная модель и модель маятниковая ${ }^{4}$.

\footnotetext{
${ }^{3}$ Хазанов О. В. Феномен религиозного историзма: некоторые подходы к пониманию еврейской и индийской традиций. Saаrbrücken, 2011. С. 145.

${ }^{4}$ См. подробно о них: Рашковский Е. Б. Востоковедная проблематика в культурно-исторической концепции А. Дж. Тойнби. M., 1976. C. 31-59.
} 


\section{Исторический журнал: научные исследования № 4 (16) • 2013}

DOI: $10.7256 / 2222-1972.2013 .4 .9081$

Циклическая модель, укоренённая в разных религиозных традициях, описывает историческое время как движение от рождения мира до его гибели, т. е. цикл движения от небытия к бытию и возврату в небытие. В наиболее развитом виде модель присутствует в индийской философской традиции, где дополняется представлением об историческом регрессе в ходе эволюции человеческого общества: регресс связан с постепенным упадком религиозного закона (дхармы) от одной из четырёх эпох к другой. Сходный циклизм существовал и в античных представлениях об историческом времени ${ }^{5}$. Линейная модель также ведёт происхождение от восточных религиозных традиций - зороастрийской и ближневосточной, и заключается в представлении о движении человечества от тьмы к свету, от зла к добру, спасению, преображению и, соответственно, о возможности развития, от которого неотъемлема векторность исторического процесса. Именно такое - восточное по происхождению - моделирование истории общества - стало неотъемлемой частью европейского и - шире - западного научного познания и воспринимается по сей день «как исключительный атрибут европейской куль туры» ${ }^{6}$. Наконец, третья модель, характерная для китайской куль туры, - маятниковая: «представление о движении как колебании по типу “вперёд - назад” с тяготением к постоянному центру, что при смещении градуса образует круг: движение не в одной, а в смещающихся плоскостях; один круг заходит на другой. И так без конца» (Т. П. Григорьева) ${ }^{7}$. Это своеобразное соединение двух первых моделей не оставляет возможностей объяснять эволюцию общества и возможности изменения людьми наличного бытия.

Что даёт студенту-социологу знание этого материала? Прежде всего в методологическом и логическом плане - уход от аристотелевского и эвклидова «закона исключённого третьего», который допускает только два разумных суждения - $\mathrm{S} \mathrm{есть} \mathrm{P}$ или $\mathrm{S}$ не есть $\mathrm{P}$, третьего не дано $(\mathrm{A}=\mathrm{A} \neq \mathrm{B})^{8}$ и развитие (разумеется, при надлежащем усилии самого студента) гибкости теоретического мышления. Кроме того, знание типов моделирования исторического времени позволяет лучше понять теоретические построения философов, социологов, культурологов, религиоведов, - с которыми сту денты

\footnotetext{
${ }^{5}$ См. Лосев А. Ф. Античная философия истории. М., 1977.

${ }^{6}$ Рашковский Е. Б. Востоковедная проблематика... С. 39.

${ }^{7}$ Роль традиций в истории и культуре Китая. М., 1972. С. 96.

${ }^{8}$ См. об этом: Померанц Г. С. Живучесть древних основ // Знамя. 2004. № 8; Померанц Г. С. Выход из транса. М., 2010. C. 304-306
}

знакомятся в рамках иных дисциплин - истории социологии, социологии культуры, социологии религии, этносоциологии и многих других. Так, можно ли до конца понять теорию социальной стратификации и мобильности П. А. Сорокина или его же теорию смены типов культуры, не зная о циклической модели исторического времени? А между тем складывается впечат ление, что сту денты слышат об этой модели впервые только в курсе методологии социального познания...

Другой пример - невнимание к востоковедному содержанию теоретических построений классиков социологии. Здесь речь пойдёт о К. Марксе и одной из типологий обществ, которую называют «марксистской». В ответ на вопрос о формациях, задаваемый из года в год при освещении одной из тем курса этносоциологии, сту денты неизменно перечисляют: «первобытная, рабовладельческая, феодальная, капиталистическая, коммунистическая», даже не зная, что это - печально знаменитая «пятичленка» из «Краткого курса истории ВКП(б)», имеющая прямое отношение к сталинской версии марксизма и «истмату», но не к Марксу . . Эта схема продолжает воспроизводиться в учебниках и пособиях, в Интернет-пространстве (за небольшими исключениями) - словно и не было ожесточённых дискуссий вокруг марксовой концепции «азиатского» способа производства ${ }^{9}$ в 1960-х годов, которые быстро сворачивались «сверху» - из-за того, что он поразительно напоминал советскую централизованную экономику и сращение власти и собственности в командно-административной системе управления.

О тех дискуссиях между историками-марксистами, пытавшимися решить вопрос о том, существовала ли рабовладельческая формация на Востоке, вспоминает Г. С. Померанц: «Сторонники рабовладения высасывали из истории Китая и древней Индии подходящие цифры, аболиционисты ставили всё под сомнение. ...Древние индийцы различали три вида ума, а раба и слугу (к отчаянию историков-марксистов) смешивали. В конце концов один из сторонников умозрительной схемы исторического процесса... нашёл забавный выход из положения. Он признал, что рабов в Индии было немного (факт очевидный), но так как рабство существовало, то каждый бедняк чувствовал себя под угрозой стать рабом, быть обращённым

\footnotetext{
${ }^{9}$ В предисловии к работе «К критике политической экономии» (1858) Маркс пишет: «В общих чертах азиатский, античный, феодальный и современный, буржуазный, способы производства можно обозначить как прогрессивные эпохи экономической общественной формации». Не менее важна освещающая эту тему его работа «Формы, предшествующие капиталистическому производству».
} 
в рабство. ... Бросалось в г лаза, что гораздо легче найти рабовладельческую формацию в Соединённых Штатах или в России около 1850 г .: цифры здесь надёжные и внушительные. Но они никому не нужны, не вовремя торчат» ${ }^{10}$.

На рубеже 1980-х гг. дискуссия возникла вновь, в контексте обсуждения возможностей цивилизационного исследования обществ. В ходе её историквостоковед Л. Б. Алаев сделал два важных замечания. «Что касается Древнего Востока, - сказал он на круглом столе, - то самые упорные сторонники «пятичленки» отказываются считать его рабовладельческим» ${ }^{11}$. Другое замечание теоретического характера касалось условности самих наименований формаций у Маркса: «Выдвинутая как обобщение исторического пусти Европы, теория формаций была просто без всяких оговорок и доработок перенесена на весь мир и затрещала, как детская одежда, натягиваемая на взрослого человека» 12 .

Марксова концепция азиатского и античного способов производства была блестяще применена отечественным востоковедом Л. С. Васильевым в теоретическом осмыслении истории стран Востока ${ }^{13}$. К наиболее значимым, на мой взг ляд, теоретическим разработкам последнего времени о роли восточного / азиатского способа производства, относится работа Е. Б. Рашковского «Шифрограмма истории: к востоковедному прочтению ветхозаветных текстов» 14 . Более того, концепция азиатского способа производства продолжает сохранять методологическую актуальность и научно-теоретическую ценность как «эвристическая модель востоковедного исторического познания, сама по себе ничего не решающая, но небесполезная в плане понимания некоторых основополагающих, "матричных” особенностей традиционных обществ Востока», - отмечает Е. Б. Рашковский ${ }^{15}$. Добавлю к этому - и понимания особенностей и перипетий модернизации незападных и периферийных Западу обществ (к последним относится и Россия), и понимания особенностей социальной структуры и управления в тоталитарных режимах, в которых господствует госу дарственная форма собственности, планирование и эксплуатация зависимого от государства и принципиально несвободного населения. Наконец, понимания тех препятствий,

\footnotetext{
10 Померанц Г. С. Выход из транса. С. 143-144.

11 Формации или цивилизации? (Материалы круглого стола) // Вопросы философии. 1989. № 10. С. 36.

12 Там же.

13 Васильев Л. С. История Востока. В 2-х тт. М., 1993.

${ }^{14}$ Рашковский Е. Б. Смыслы в истории... М., 2008. С. 35-65.

15 Там же. С. 46.
}

с которыми столкнулась Россия периода перехода к рыночной экономике.

Однако все разработки, вплоть до новейших, продолжают существовать независимо от вузовского гуманитарного образования и остаются востребованными лишь в научных кругах. Более того, междисциплинарный характер этих разработок, их значимость для социологического, куль турологического, религиоведческого и философского познания и образования (не только исторического!), по моим впечатлениям, не воспринят, и из-за этого не осваивается ${ }^{16}$.

Когда в курсе социологии рассматриваются теории и типы социальной стратификации, то чаще всего здесь возникает востоковедная, точнее индологическая проблематика, поскольку одной из систем стратификации называют кастовую систему. Это бесспорно - «кастовые» принципы организации общества обнаруживаются во многих традиционных обществах (Япония, народы Африки), сохраняются в модернизирующихся и могут быть эмпирически зафиксированы в странах модернизированных. Как пишет ведущий отечественный специалист по кастовой системе, петербургский индолог Е. Н. Успенская, «Когда мы замечаем, как в обществах постмодерна вновь горячо почитается статус рождения и на этой основе выстраиваются традиционные виды стратификации и иерархии, в том числе между этническими общностями (гастарбайтеры везде заняты на непрестижных видах работы, китайские общины часто специализируются на ресторанном бизнесе и т . д.), то это тоже «каста», это работают её принципы воспроизводства, коренящиеся в самых архетипических началах человеческого мироощущения, и прежде всего в универсально значимой приверженности к родственным связям» 17 .

В качестве классического и общеизвестного примера в учебниках описывается индийская кастовая система, и кастами называют структуры, которые неизвестны «самим индийцам не только

\footnotetext{
${ }^{16}$ Вспоминается эпизод из моей студенческой жизни середины 1990-х: при изучении курса новейшей истории Востока на историческом факультете преподаватель не рекомендовал готовиться к экзамену по «Истории Востока» Л. С. Васильева («вы его (учебник - Т. С.) не берите»), однокурсники при остром дефиците новых изданий в провинциальных библиотеках ограничились советскими учебниками для вузов. К тому моменту я уже с удовольствием прочитала этот двухтомник, который многое дал мне для моих тогдашних студенческих и - нынешних востоковедных занятий. Совет исходил от преподавателя, воспитанного в традициях марксистского подхода к истории...

${ }^{17}$ Успенская Е. Н. Антропология индийской касты. СПб., 2010. C. 5 .
} 


\section{Исторический журнал: научные исследования № 4 (16) • 2013}

DOI: $10.7256 / 2222-1972.2013 .4 .9081$

терминологически, но и в качестве социальной группы» 18 - брахманов (жрецов), кшатриев (правителей и воинов), вайшьев (торговцев и посредников) и шу др (земледельцы и ремесленники). Из-за «параллельности» сосуществования по отношению друг у другу социологической и исторической наук (при той социологизированности последней, что характерна для отечественной марксистской традиции), достижения отечественной индологии в изучении кастовой системы Индии (Л. Б. Алаев, М. К. К удрявцев, А. А. К уценков, Е. Н. У спенская, Е. С. Юрлова) ${ }^{19}$ остаются неизвестны молодым социологам, как впрочем, и историкам. В учебниках социологии воспроизводится европейская «теория кастовой системы», сложившаяся к началу XX века и являющаяся резуль татом развития анг лийской колониальной науки и побуждающая изучать «вымышленную» касту (Н. Дёркс), а не реально существующие в Индии варны (иерархически выстроенные статусные категории) и джати (основные ячейки кастового общества в их этносоциальном измерении) ${ }^{20}$. В итоге интереснейший социологический материал о возникновении, эволюции и современном состоянии индийского кастового общества, представляющего собою сообщество индуистов по вероисповеданию (82 \% населения страны), но буквально втягивающих в орбиту кастовой организации социального взаимодействия инорелигиозные общины, а также материал о групповой вертикальной мобильности джати, стоящих внизу социальной иерархии - процессе санскритизации, выработанном в брахманизме с древнейших времён и действующем по сей день, - всё это остаётся вне поля зрения и кругозора молодого социолога.

И это при широчайших возможностях анализа и понимания социальных процессов, связанных с социальными статусами и ролями в современных обществах (включая Россию), - которое предоставляет знание именно индийской специфики варново-джатной структуры. Мне возразят: зачем перегружать сознание студентов, тем более что мы не готовим востоковедов? Но явления, характерные для сегрегации и взаимодействия по кастовым принци-

\footnotetext{
18 Там же. С. 6.

${ }^{19}$ Алаев Л. Б. Сельская община в Северной Индии. Основные этапы эволюции. М., 1981; Кудрявцев М. К. Община и каста в Хиндустане (Из жизни индийской деревни). М., 1971; Кудрявцев М. К. Кастовая система в Индии. М., 1992; Куценков А. А. Эволюция индийской касты. М., 1983; Успенская Е. Н. Раджпуты. Традиционное общество. Государственность. Культура. СПб., 2003; Успенская Е. Н. Антропология индийской касты. СПб., 2010; Юрлова Е. С. От неприкасаемых к далитам. Очерки истории, идеологии и политики. М., 2003

20 См. Успенская Е. Н. Антропология индийской касты. СПб., 2010. C. 6-19
}

пам, встречались и встречаются и в странах Запада, и их фиксируют не только учёные, но и писатели ${ }^{21}$.

Не менее актуально это знание и в анализе современной российской социальной структуры: «коренные жители» городов считают непрестижными для себя те области тру довой деятельности, которые в кастовом обществе Индии в основном считаются «ритуально нечистыми» и «оскверняющими» - работу дворника, уборщика и т . д.: аргументом выдвигается низкая оплата этого тру да. Ниша занята - особенно в крупных городах - мигрантами, без которых общество, с одной стороны, прожить не может (как индийское - без неприкасаемых), а с другой - презирает и лелеет в отношении них стереотипы чужака и врага.

Вопросы и темы, связанные с модернизацией незападных традиционных обществ, трансформациями их социальной структуры, общественного сознания, становлением политических институтов и развитием новой модернизированной куль туры, изучаемые в отечественном востоковедении, также остаются за пределами учебных курсов и дисциплин. И дело не в сокращении аудиторных часов и переносе акцента на самостоятельную подготовку студента в современном российском высшем образовании. Большинство курсов гуманитарного цикла - скорее теоретические и ознакомительные, однако в них теоретически интерпретируются процессы и явления, характерные для Запада и распространяющиеся благодаря ему по всему миру. Как правило, студенты с интересом относятся к информации о том, как западные ценности, институты и нормы воспринимаются, усваиваются и / или отторгаются на Востоке, и почему в разных культурах всё это происходит неодинаково. Например, в Японии «наиболее удачливых бизнесменов отличают самурайские качества - в том смысле, что они никогда не побоятся принять непростое решение и не дрогнут , испугавшись дурных вестей», а подготовка бизнесменов и менеджеров включает освоение традиционной этики и искусств, в т . ч. военных $^{22}$. В данном случае очевидно умение усваивать новое, опираясь на выработанные веками социокультурные традиции.

\footnotetext{
${ }^{21}$ Кастовый характер взаимодействия и кастовую же изоляцию показал в романе «Остров фарисеев» Джон Голсуорси, а Джордж Оруэлл в очерках «Англичане», описывая английскую классовую систему, отмечает, что в стране «бродит призрак кастовой системы», а чтобы понять деление на высший, средний и рабочий классы, надо принять во внимание деление внутри различных классов (См.: Оруэлл Дж. Англичане // Оруэлл Дж. Памяти Каталонии. Эссе. М., 2003. С. 230).

22 Харфорд Дж. Новые самураи // Курьер ЮНЕСКО. 1994. Июнь. С. 34.
} 


\section{Междисциплинарные исследования}

DOI: $10.7256 / 2222-1972.2013 .4 .9081$

Вместе с этим можно показать, какую роль в модернизации незападных стран играет распространение европейского образования и освоение достижений европейской культуры. С одной стороны, представители местных элит осваивают современные модели рационально-научного мышления, но именно знакомство с другими куль турами - западными в обликах конкретных куль тур европейских стран - обращает элиты к осмыслению и исследованию собственных цивилизационных традиций и попытками встроить их в современность, сделать основой развития социума и куль туры, хотя иной раз и превращается в свою противоположность - традиционализм и фундаментализм.

При изучении курса «Социологические проблемы изучения общественного мнения» я считаю важным показать, что в восточных странах генезис общественного мнения, связанный с формированием личности нового типа и разложения социальных структур традиционного общества ${ }^{23}$ и становлением гражданского общества идёт иначе, чем на Западе. Так, в восточных обществах, попавших в орбиту западного влияния, носителями общественного мнения поначалу оказываются узкие социально активные группы населения, прежде всего элиты экономические (включившиеся в систему рыночных отношений) и культурные (получившие образование по западному образцу (educated men, а не традиционные learned men)). Именно в этой среде местных элит можно наблюдать формирование свободной автономной личности - носителя личного мнения, свободного от давления традиционного социального контроля. По мере продвижения модернизационных процессов, охватывающих всё более широкие круги и слои общества, можно говорить о вовлечении в процесс формирования общественного мнения более широких кругов и слоёв общества. Тем более что влиянием западных моделей мышления восточные интеллектуалы начинают видеть многие явления и процессы, происходящие в их обществах, как проблемы, и желать их решения.

Приведённые примеры - всего лишь частные случаи, иллюстрирующие общую тенденцию: относительно независимое друг от друга существование гуманитарных дисциплин в системе образования и - научных направлений и школ, разрабатывающих востоковедную проблематику . Эти примеры касаются г лавным образом социологических дисциплин, но при желании можно найти аналоги в других областях гуманитарного знания. Я до-

${ }^{23}$ См.: Федотова Л. Н. Общественное мнение как плацдарм для связей с общественностью. Учебное пособие. М., 2010. С. 19-24 пускаю, что в моих размышлениях есть большая доля субъективности учёного, занятого востоковедными исследованиями и иначе видящего многие вещи, кажущиеся самоочевидными носителям западной по происхождению и содержанию модели мышления. Но всё же позволю себе некоторые обобщения.

Во-первых, востоковедные темы востребованы в сту денческой среде - об этом можно су дить не только по собственному опыту и опыту моих коллег, но и по желанию студентов самостоятельно изучить ту или иную тему в её «восточном» измерении, подготовить доклад на конференцию, и - по интересу, который вызывают подобные доклады у аудитории. Но беда в том, что информация для этих докладов добывается не из трудов отечественных востоковедов (в которых в том числе обобщается опыт зарубежной ориенталистики, - не говоря о зарубежных исследованиях!), а из книг и интернет-сайтов, имеющих самое от далённое отношение к серьёзной академической науке 24 . Думается, что именно интеграция востоковедного знания в гуманитарное образование - это вполне адекватное «противоядие» разного рода околонаучной и непрофессиональной информации, а также способ обучения критическому мышлению буцщих специалистов в разных сферах.

Во-вторых, не менее важно присутствие востоковедного знания в вузовском образовании в просветительских целях. Великое множество негативных стереотипов в отношении других народов, культур, стран, религий имеют причиной элементарное незнание (а иной раз и нежелание знать!) и - узость мышления. Востоковедение, помимо всего прочего, воспитывает уважение к Другим народам и культурам, расширяет границы мышления и прививает навыки понимания Другого.

Наконец, в-третьих, востоковедное знание помогает лучше осознавать универсальное единство человечества вместе с уникальностью развития каждого народа и каждой цивилизации, и в этом контексте понимать универсальное и особенное в развитии собственной страны - России. В этом смысле почвеннические и традиционалистские рассуждения об «особом пути» страны окажут-

\footnotetext{
${ }^{24}$ Хотя встречаются и исключения: недавно в сети мне попался «реферат» (вариант - «курсовая»), который слово в слово от названия до ссылок на источники на английском языке на книги, которые есть порой в единственном экземпляре в российских научных библиотеках научных столиц Москвы и Петербурга - повторяет одну из моих статей, вышедших в журнале «Вопросы философии». Остаётся только надеяться, что преподаватель, которому принесут мою статью в виде «реферата» или «курсовой», не забудет проверить его на плагиат...
} 


\section{Исторический журнал: научные исследования № 4 (16) • 2013}

\section{DOI: $10.7256 / 2222-1972.2013 .4 .9081$}

ся не уникальной чертой российской цивилизации и ментальности её народа, а направлением мысли, характерным для многих восточных обществ, решающих проблему соотнесения себя с Западом. А растущая ностальгия людей по советским временам будет объяснена не «исконной приверженностью» россиян к благополучию под патерналистским крылом «сильного госу дарства», а живучестью традиционных - вплоть до архаических! - структур организации общества ${ }^{25}$, ценностей

25 Одной из самых содержательных отечественных работ на эту тему я считаю фундаментальный труд И. Г. Яковенко (См.: Яковенко И. Г. Познание России: цивилизационный анализ. M., 2012). традиционного сознания и куль турных установок, характерных для восточных обществ в разных вариантах, но универсально сходных...

Находясь на перекрёстке Востока и Запада, Россия предоставляет уникальные возможности понимать и тот , и другой. Для этого понимания много сделали видные отечественные учёные - как исследованиями российской истории и куль туры, так и исследованиями стран Востока. Пришло время интегрировать это знание в сферу вузовского общегуманитарного образования и тем самым расширить возможности понимания новыми поколениями и самих себя, и других народов и стран.

\section{Библиография:}

1. Алаев Л. Б. Сельская община в Северной Индии. Основные этапы эволюции. М., 1981.

2. Васильев Л. С. История Востока. В 2-х тт. М., 1993.

3. Кудрявцев М. К. Кастовая система в Индии. М., 1992.

4. Кудрявцев М. К. Община и каста в Хиндустане (Из жизни индийской деревни). М., 1971.

5. Куценков А. А. Эволюция индийской касты. М., 1983.

6. Лосев А. Ф. Античная философия истории. М., 1977.

7. Оруэлл Дж. Англичане // Оруэлл Дж. Памяти Каталонии. Эссе. М., 2003.

8. Померанц Г. С. Выход из транса. М., 2010.

9. Померанц Г. С. Живучесть древних основ // Знамя. 2004. № 8.

10. Рашковский Е. Б. Востоковедная проблематика в культурно-исторической концепции А. Дж. Тойнби. М., 1976.

11. Рашковский Е. Б. Смыслы в истории: Исследования по истории веры, познания, культуры. М., 2008. С. 35-65

12. Роль традиций в истории и культуре Китая. М., 1972.

13. Сабато Э. Умение удивляться // Курьер ЮНЕСКО. 1990. Октябрь.

14. Успенская Е. Н. Антропология индийской касты. СПб., 2010.

15. Успенская Е. Н. Раджпуты. Традиционное общество. Государственность. Культура. СПб., 2003.

16. Федотова Л. Н. Общественное мнение как плацдарм для связей с общественностью. Учебное пособие. М., 2010.

17. Формации или цивилизации? (Материалы круглого стола) // Вопросы философии. 1989. № 10.

18. Хазанов О. В. Феномен религиозного историзма: некоторые подходы к пониманию еврейской и индийской традиций. Saarbrücken, 2011.

19. Харфорд Дж. Новые самураи // Курьер ЮНЕСКО. 1994. Июнь.

20. Юрлова Е. С. От неприкасаемых к далитам. Очерки истории, идеологии и политики. М., 2003.

21. Яковенко И. Г. Познание России: цивилизационный анализ. М., 2012.

22. Ясперс К. Смысл и назначение истории. Пер. с нем. 2-е изд. М., 1994.

\section{References:}

1. Alaev L. B. Sel'skaya obschina v Severnoy Indii. Osnovnye etapy evolyucii. M., 1981.

2. Vasil'ev L. S. Istoriya Vostoka. V 2-h tt. M., 1993.

3. Kudryavcev M. K. Kastovaya sistema v Indii. M., 1992.

4. Kudryavcev M. K. Obschina i kasta v Hindustane (Iz zhizni indiyskoy derevni). M., 1971.

5. Kucenkov A. A. Evolyuciya indiyskoy kasty. M., 1983.

6. Losev A. F. Antichnaya filosofiya istorii. M., 1977.

7. Oruell Dzh. Anglichane // Oruell Dzh. Pamyati Katalonii. Esse. M., 2003. 


\section{Междисциплинарные исследования}

DOI: 10.7256/2222-1972.2013.4.9081

8. Pomeranc G. S. Vyhod iz transa. M., 2010.

9. Pomeranc G. S. Zhivuchest' drevnih osnov // Znamya. 2004. № 8.

10. Rashkovskiy E. B. Vostokovednaya problematika v kul'turno-istoricheskoy koncepcii A. Dzh. Toynbi. M., 1976.

11. Rashkovskiy E. B. Smysly v istorii: Issledovaniya po istorii very, poznaniya, kul'tury. M., 2008. S. 35-65

12. Rol' tradiciy v istorii i kul'ture Kitaya. M., 1972.

13. Sabato E. Umenie udivlyat'sya // Kur'er YuNESKO. 1990. Oktyabr'.

14. Uspenskaya E. N. Antropologiya indiyskoy kasty. SPb., 2010.

15. Uspenskaya E. N. Radzhputy. Tradicionnoe obschestvo. Gosudarstvennost'. Kul'tura. SPb., 2003.

16. Fedotova L. N. Obschestvennoe mnenie kak placdarm dlya svyazey s obschestvennost'yu. Uchebnoe posobie. M., 2010.

17. Formacii ili civilizacii? (Materialy kruglogo stola) // Voprosy filosofii. 1989. № 10.

18. Hazanov O. V. Fenomen religioznogo istorizma: nekotorye podhody k ponimaniyu evreyskoy i indiyskoy tradiciy. Saarbrücken, 2011.

19. Harford Dzh. Novye samurai // Kur'er YuNESKO. 1994. Iyun'.

20. Yurlova E. S. Ot neprikasaemyh k dalitam. Ocherki istorii, ideologii i politiki. M., 2003.

21. Yakovenko I. G. Poznanie Rossii: civilizacionnyy analiz. M., 2012.

22. Yaspers K. Smysl i naznachenie istorii. Per. s nem. 2-e izd. M., 1994 